\title{
Role of Glucose on Breast Cancer Patients
}

\author{
Ishita Saha ${ }^{1}$ and Rabindra Nath Das ${ }^{2 *}$ \\ ${ }^{1}$ Department of Physiology, Calcutta Medical College and Hospital, India \\ ${ }^{2}$ Department of Statistics, The University of Burdwan, India
}

Submission: October 15, 2020; Published: December 14, 2020

*Corresponding author: Rabindra Nath Das, Department of Statistics, The University of Burdwan, Burdwan, West Bengal, India

\section{Editorial}

Cancer and diabetes mellitus (DM) are frequently occurring diseases with frightening impact on human health worldwide. In epidemiological studies, it is observed that people with DM are always at higher risk for several types of cancer [1-4]. Some research reports have pointed that there is a direct link between overweight and cruelty of breast cancer (BC) [5-7]. Correlation between the $\mathrm{BC}$ prognosis and metabolic syndrome has been reported in [8]. The following inquiries are surveyed in the present editorial report.

i. Are there any effects of glucose with BC patients and BC markers?

ii. If it is affirmative, what are the relations of glucose with $\mathrm{BC}$ patients and $\mathrm{BC}$ markers?

iii. What are the effects of glucose on BC patients and BC markers?

The above queries are searched in the editorial note based on a real data set of 116 normal and BC women along with 10 study variables, and the data set is available in the UCI Machine Learning Repository, and it is clearly illustrated in $[9,10]$. For immediate applications, the 10 study variables are presented as follows.

a. Age (years),

b. BMI $\left(\mathrm{kg} / \mathrm{m}^{2}\right)$,

c. Homeostasis model assessment score insulin resistance (HOMA-IR),
d. Insulin $(\mu \mathrm{U} / \mathrm{mL})$,
e. Glucose (mg/ dL),
f. Resistin (ng/mL),
g. Adiponectin $(\mu \mathrm{g} / \mathrm{mL})$,

h. Monocyte chemoattractant protein-1 (MCP-1) (pg/dL),

i. Leptin $(\mathrm{ng} / \mathrm{mL})$,

j. $\quad$ Patient type (PT) (1=Healthy controls; $2=$ BC patients).

The above inquiries can only be surveyed by modeling glucose on the rest factors. Note that glucose is a positive continuous heteroscedastic random variable that can be modeled by joint generalized linear models (JGLMs) under both the lognormal and gamma distributions $[11,12]$. Joint gamma glucose model fit gives better results than lognormal fit, so only the gamma model fit outcomes are displayed in Table 1. In addition, the data generated glucose gamma model fit is justified by the graphical plots in Figure 1. Figure 1 (a) reveals the absolute residuals plot with respect to glucose predicted values, which shows that all absolute residuals are randomly located at a single point except only two residuals. The smooth fitted line is exactly a flat straight line, except the right end which is increasing as a higher residual is located at the right boundary. Figure 1(b) presents the mean normal probability plot of glucose in Table 1. These two plots do not reveal any lack of fit. So, the gamma fitted glucose model (Table 1 ) is close to its true model. Gamma fitted mean \& dispersion models of glucose are as follows.

Gamma fitted glucose mean 0 model (from Table 1) is

$=\exp (4.3933+0.625$ HOMA-IR -0.128 Insulin +0.022 Tyes of patients + 0.004 LEPT

+ 0.001 ADIP - 0.002 HOMA-IR*LEPT - 0.001 LEPT*ADIP),

and the Gamma fitted glucose variance () model (from Table 1) is

$=\exp (-8.844+2.005$ HOMA-IR +0.053 Age -0.007 Age*HOMA-IR - 0.162 Insulin

+ 0.129 REST - 0.039 LEPT - 0.002 Age*REST- 0.001 MCP-1 0.011 Insulin*HOMA-IR). 


\section{Cancer Therapy \& Oncology International Journal}

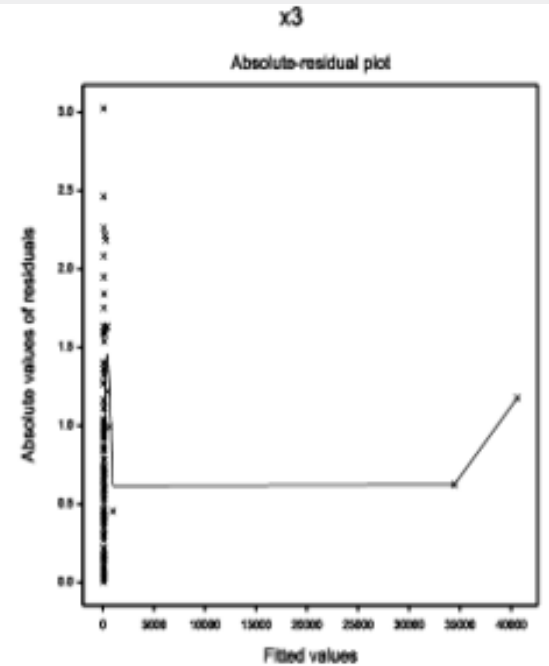

(a)

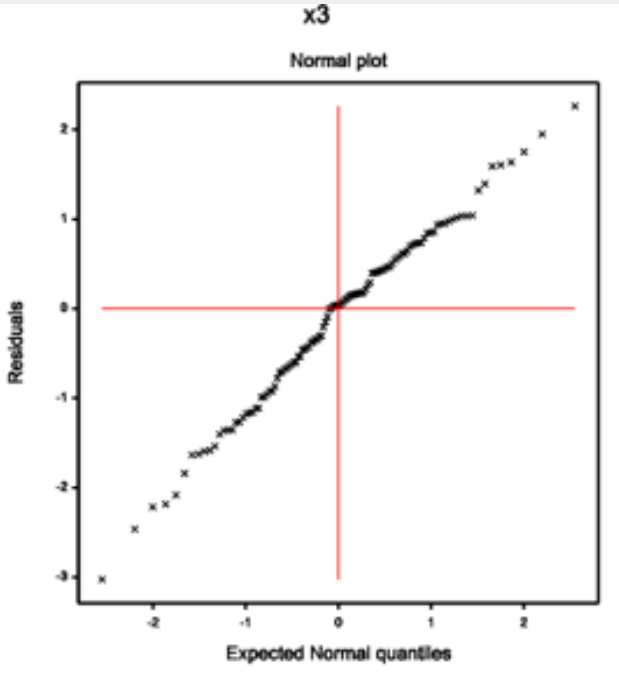

(b)

Figure 1: For the joint gamma glucose fitted model (Table 1), the (a) absolute residuals plot with respect to the glucose fitted values, and (b) the normal probability plot for the glucose mean model.

From the above glucose fitted mean \& dispersion models (i.e., can be reported.

Table 1), the following relationships of glucose with BC markers

Table 1: Results for mean and dispersion models of glucose fitting.

\begin{tabular}{|c|c|c|c|c|c|}
\hline \multirow{2}{*}{ Model } & \multirow{2}{*}{ Variables } & \multicolumn{4}{|c|}{ From gamma fit } \\
\hline & & Estimate & s.e. & t-value & p-value \\
\hline \multirow{8}{*}{ Mean } & Constant & 4.393 & 0.020 & 218.02 & $<0.001$ \\
\hline & Insulin (INSU) & -0.128 & 0.006 & -22.58 & $<0.001$ \\
\hline & HOMA-IR & 0.625 & 0.028 & 22.03 & $<0.001$ \\
\hline & TYOP & 0.022 & 0.009 & 2.32 & 0.022 \\
\hline & LEPT & 0.004 & 0.001 & 6.21 & $<0.001$ \\
\hline & HOMA-IR *LEPT & -0.002 & 0.001 & -7.12 & $<0.001$ \\
\hline & ADIP & 0.001 & 0.001 & 0.78 & 0.437 \\
\hline & LEPT*ADIP & -0.001 & 0.001 & -1.72 & 0.088 \\
\hline \multirow{10}{*}{ Dispersion } & Constant & -8.844 & 1.019 & -8.68 & $<0.001$ \\
\hline & Age & 0.053 & 0.016 & 3.31 & 0.001 \\
\hline & HOMA-IR & 2.005 & 0.393 & 5.11 & $<0.001$ \\
\hline & Age* HOMA-IR & -0.007 & 0.003 & -2.19 & 0.031 \\
\hline & Insulin (INSU) & -0.162 & 0.065 & -2.51 & 0.014 \\
\hline & LEPT & -0.039 & 0.009 & -4.29 & $<0.001$ \\
\hline & REST & 0.129 & 0.055 & 2.33 & 0.022 \\
\hline & Age* REST & -0.002 & 0.001 & -2.08 & 0.040 \\
\hline & INSU* HOMA-IR & -0.011 & 0.003 & -3.79 & 0.002 \\
\hline & MCP-1 & -0.001 & 0.001 & -2.57 & 0.012 \\
\hline
\end{tabular}

Mean glucose levels are directly related with patient type $(\mathrm{P}=0.022)$, interpreting that mean glucose levels are higher for $\mathrm{BC}$ women than normal. It concludes that $\mathrm{BC}$ women have greater risk of DM. Mean glucose levels are directly related with leptin $(\mathrm{P}<0.001)$, implying that mean glucose levels rise as leptin levels increase. Mean glucose levels are directly related with 


\section{Cancer Therapy \& Oncology International Journal}

HOMA-IR( $(\mathrm{P}<0.001)$, concluding that glucose levels rise as HOMAIR levels increase. Mean glucose levels are inversely related to the interaction effect of HOMA-IR and leptin (HOMA-IR*LEPT) $(\mathrm{P}<0.0001)$, indicating that mean glucose levels increase as HOMAIR*LEPT decreases. Mean glucose levels are inversely related to the interaction effect of leptin and adiponectin (LEPT*ADIP) $(\mathrm{P}=0.088)$, concluding that mean glucose levels rise as the interaction effect LEPT*ADIP decreases. Mean glucose levels are inversely related with Insulin levels $(\mathrm{P}<0.001)$, concluding that mean glucose levels rise as insulin levels decrease, which is occurring in practice. Variance of glucose levels is directly related with HOMA-IR $(\mathrm{P}<0.001)$, indicating that subjects with higher HOMA-IR levels have highly scattered glucose levels. Variance of glucose levels is directly related with resist in levels $(\mathrm{P}=0.022)$, indicating that subjects with higher resistin levels have highly scattered glucose levels.

Variance of glucose levels is inversely related with leptin levels $(\mathrm{P}<0.001)$, concluding that subjects with lower leptin levels have highly scattered glucose levels. Variance of glucose levels is inversely related with MCP-1 levels $(\mathrm{P}=0.012)$, interpreting that subjects with lower MCP-1 levels have highly scattered glucose levels. Variance of glucose levels is inversely related with Age*HOMA-IR ( $\mathrm{P}=0.031)$, or INSU* HOMA-IR ( $\mathrm{P}=0.002)$, or Age*REST $(\mathrm{P}=0.040)$, concluding that variance of glucose levels is rises as Age*HOMA-IR, or INSU*HOMA-IR, or Age*REST decreases.

All the above conclusions are drawn from the appropriate glucose levels fitting model (Table 1), where the standard errors of all the estimates (Table 1) are very small, indicating that estimates are stable. From the above it is observed that mean and variance of glucose levels are highly associated with many BC markers and their joint interaction effects. It can be concluded that glucose levels rise for breast cancer women, along with the increase of HOMA-IR, leptin, and decrease of insulin, HOMA-IR*leptin, leptin*adiponectin. From this report medical practitioners and BC women will be benefitted. BC women should always care about their glucose levels regularly.

\section{Conflict of Interest}

The authors confirm that this article content has no conflict of interest.

\section{References}

1. Giovannucci E, Harlan DM, Archer MC, Richard M Bergenstal, Susan M Gapstur, et al. (2010) Diabetes and cancer a consensus report. Diabetes Care 33(7): 1674-1685.

2. World Cancer Report (2008) Boyle P, Bernard L, Eds. Cedex, France, World Health Organization, International Agency for Research on Cancer.

3. Shao S, Gill AA, Zahm SH, Jatoi I, Shriver CD, et al. (2018) Diabetes and Overall Survival among Breast Cancer Patients in the U.S. Military Health System. Cancer Epidemiol Biomarkers Prev 27(1): 50-57.

4. Lopez AD, Mathers CD, Ezzati M, Jamison DT, Murray CJ (2006) Global and regional burden of disease and risk factors, 2001: systematic analysis of population health data. Lancet 367: 1747-1757.

5. Kulie T, Slattengren A, Redmer J, Counts H, Eglash A, et al. (2011) Obesity and women's health: an evidence-based review. J Am Board Fam Med 24: 75-85.

6. Azvolinsky A (2014) Cancer prognosis: role of BMI and fat tissue. J Natl Cancer Inst 106: dju177.

7. Das RN, Lee Y, Mukherjee S, Oh S (2019) Relationship of body mass index with diabetes \& breast cancer biomarkers. J Diabetes and Management 9(1): 163-168.

8. Berrino F, Villarini A, Traina A, Bonanni B, Panico S, et al. (2014) Metabolic syndrome and breast cancer prognosis. Breast Cancer Res Treat 147(1): 159-165.

9. Crisóstomo J, Matafome P, Santos-Silva D, Gomes AL, Gomes M, et al Hyperresistinemia and metabolic dysregulation: a risky crosstalk in obese breast cancer. Endocrine 53(2): 433-442.

10. Patrício M, Pereira J, Crisóstomo J, Matafome P, Gomes M, et al. (2018) Using Resistin, glucose, age and BMI to predict the presence of breast cancer. BMC Cancer 18(1): 18-29.

11. Lee, Y, Nelder JA, Pawitan Y (2017) Generalized Linear Models with Random Effects (Unified Analysis via H-likelihood) (second edn). Chapman \& Hall, London, UK.

12. Das RN, Lee Y (2009) Log-normal versus gamma models for analyzing data from quality-improvement experiments. Quality Engineering 21(1): 79-87.

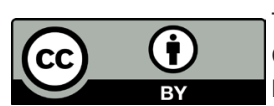

This work is licensed under Creative Commons Attribution 4.0 License DOI:10.19080/CTOIJ.2020.17.555967
Your next submission with Juniper Publishers will reach you the below assets

- Quality Editorial service

- Swift Peer Review

- Reprints availability

- E-prints Service

- Manuscript Podcast for convenient understanding

- Global attainment for your research

- Manuscript accessibility in different formats

( Pdf, E-pub, Full Text, Audio)

- Unceasing customer service

Track the below URL for one-step submission https://juniperpublishers.com/online-submission.php 